\title{
EFEITO DA IDADE DA MATRIZ SOBRE O RENDIMENTO E QUALIDADE DA CARNE DE FRANGOS DE CORTE ${ }^{1}$
}

\author{
José Antonio DALANEZI², Ariel Antonio MENDES ${ }^{2, *}$, Edivaldo Antonio GARCIA², Rodrigo Garofallo GARCIA ${ }^{2}$,
}

\author{
Joerley MOREIRA², Tania Sayuri TAKITA², Ibiara Correia de Lima Almeida PAZ ${ }^{2}$
}

\begin{abstract}
RESUMO
O experimento foi conduzido na Faculdade de Medicina Veterinária e Zootecnia da UNESP, Campus de Botucatu, para avaliar o efeito da idade da matriz no desenvolvimento, rendimento e qualidade da carne de frangos de corte. Ovos de matrizes da linhagen Ross $\mathrm{x}$ Ross provenientes de lotes com 29, 41, 58, 68 e 98 semanas de idade foram selecionados e incubados em idênticas condições. Após a eclosão, três mil e seiscentos pintinhos de um dia foram alojados, ao acaso, em um esquema fatorial $5 \times 2$, ou seja, 5 idades e 2 sexos, e criados até 49 dias de idade. Com 21, 28, 35, 42 e 49 dias de idade, 25 aves de cada tratamento foram selecionadas e abatidas após um período de 8 horas de jejum alimentar. De acordo com resultados obtidos, a idade da matriz afetou $(\mathrm{P}<0,05)$ a espessura do filé do peito e o rendimento de carne de peito aos 49 dias de idade, com melhores resultados para frangos originados de matrizes com 29 semanas de idade. $\mathrm{O}$ pH do peito e da perna sofreu uma variação bastante acentuada, sendo menor nas aves oriundas de matrizes mais velhas e maior nas aves oriundas de matrizes mais novas. Já a perda de peso por cozimento e a força de cizalhamento não foram afetados pela idade da matriz.

Palavras-chave: filé; peito; $\mathrm{pH}$; idade da matriz.
\end{abstract}

\section{SUMMARY}

EFFECT OF BROILER BREEDER AGE ON CARCASS YIEL AND MEAT QUALITY OF BROILER CHICKENS. The experiment was conducted at Faculdade de Medicina Veterinária e Zootecnia - UNESP - Botucatu, Brasil, in order to evaluate the effect of breeder age on development, carcass yield and meat quality of broiler chickens. Eggs from breeders of the strain Ross x Ross with 29, 41, 58, 68 and 98 weeks of age were selected and incubated at identical conditions. After hatching, three thousand and six hundred day-old-chicks were randomly assigned in a $5 \times 2$ factorial design ( 5 breeder ages and 2 sexes) and reared until 49 days of age. At 21, 28, 35, 42 and 49 days of age, 25 birds per treatment were selected and processed after 8 hours of feed withdrawal period. The results obtained showed that the breeder age affected $(\mathrm{p}<.05)$ the breast thickness and breast meat yield at 49 days of age, with broilers originated from breeders of 29 weeks of age showing the best results. Breast and leg $\mathrm{pH}$ were very affected by the treatments, with birds originated from older breeders showed the smaller values and the birds originated from the younger breeders showed the highest values. The weight cooking loss and breast shear force were not influenced by breeder age.

Keywords: steak; breast; pH; breeder age.

\section{1 - INTRODUÇÃO}

O mercado, cada vez mais competitivo entre as empresas ligadas a produção de frangos de corte, tem buscado uma ave cada vez mais pesada e pronta para o abate, em menor tempo possível. Muitas pesquisas têm sido realizadas a fim de gerar novas tecnologias nas áreas de nutrição, manejo, sanidade, ambiência e genética. $\mathrm{O}$ resultado tem sido uma melhoria constante no rendimento de peito e pernas, que apresentam uma maior quantidade de carne nas linhagens atuais, do tipo conformação. Entretanto, ainda há necessidade de mais estudos sobre os mecanismos de desenvolvimento do peito destas aves, desde o primeiro dia de vida até o abate, uma vez que o mesmo é a parte mais nobre do frango.

A idade da matriz tem influência direta na qualidade e composição dos ovos, pois matrizes jovens tendem a produzir ovos menores e, em conseqüencia, pintos menores; a taxa de eclodibilidade também é menor e a mortalidade embrionária mais alta [18, 21, 23]. Já o

\footnotetext{
Recebido para publicação em 12/01/2004. Aceito para publicação em 03/08/2004 (001274).

2. Departamento de Produção e Exploração Animal - Faculdade de Medicina Veterinária e Zootecnia - Universidade Estadual Paulista. Fazenda Lageado, s/n, Caixa Postal 560, CEP: 18618-000. Botucatu-SP-Brasil. * A quem a correspondência deve ser enviada.
}

granjeiro prefere pintos nascidos de matrizes com idades intermediárias, pois apresentam pintinhos mais homogêneos e de melhor qualidade. Maior peso corporal tem sido encontrado em frangos originados de matrizes de 51 semanas de idade, quando comparado com 35 e 63 semanas [16].

O desempenho dos frangos após a eclosão, oriundos de matrizes de diferentes idades, tem mostrado piores resultados para aves oriundas de matrizes mais novas. Autores como SINCLAIR, ROBINSON \& HARDIN [20], observaram que aves provenientes de matrizes mais jovens apresentam um peso corporal inicial menor e uma taxa de crescimento também menor. Já PEEBLES et al. [16], verificaram menor peso corporal aos 43 dias em aves nascidas de matrizes com 35 semanas, quando comparadas com matrizes de 51 e 63 semanas. No entanto, as aves oriundas das matrizes com 51 semanas de idade apresentaram melhores resultados como melhor conversão alimentar e menor mortalidade.

Alguns pesquisadores têm encontrado dados antagônicos, onde tanto a idade da matriz quanto o peso do ovo, não têm afetado o desempenho das aves na idade de abate como demonstrado por BARRETO [1], que observou uma diferença de $2,08 \mathrm{~g}$ no peso ao nascer dos pintos, o que não levou a uma diferença significativa no peso das aves aos 42 dias. Da mesma forma, CANÇADO et al. [3], observaram que o tamanho dos ovos e a relação percentual entre o peso do pinto e 
peso do ovo, não afetou o desempenho aos 42 dias de idade.

Na literatura encontram-se dados que mostram diferenças para parâmetros de qualidade da carne de aves, mas eles são mais comuns, quando analisam estudos com diferentes idades ou linhagens de frangos de corte, como nos estudos de LUBRITZ [10], POOLE et al. [17], BERRI et al. [2] e LE BIHAN-DUVAL \& MILLET [9], e não exatamente relacionados com a idade das matrizes.

Trabalho realizado por GARCIA [6], que avaliou o efeito de diferentes densidades de criação (10, 1316 aves $/ \mathrm{m}^{2}$ ) sobre os parâmetros de rendimento e qualidade da carne de peito de frangos de corte, no período de inverno e verão, verificou que as medidas físicas dos filés do peito foram afetadas pela densidade somente no período de verão, o mesmo ocorrendo com relação a maciez e perda de peso por cozimento da carne de frangos.

A incidência de defeitos em carcaça e variações no rendimento de carne foi mais influenciado pela linhagem que pelo tamanho dos ovos de suas respectivas matrizes, dados estes observados por VIEIRA \& MORAN [22].

Portanto, o presente trabalho teve como objetivo determinar o rendimento de peito e pernas, bem como algumas características de qualidade da carne do peito de frangos de corte oriundos de matrizes com 29, 41, 58, 68 e 98 semanas de idade.

\section{2 - MATERIAL E MÉTODOS}

O experimento foi realizado nas instalações experimentais da Faculdade de Medicina Veterinária e Zootecnia da UNESP, Campus de Botucatu, durante o período de 9 de agosto a 27 de setembro de 2001 .

No incubatório, após uma pré-classificação de rotina, foi pesada uma amostra de 90 ovos para cada idade de matriz a serem avaliadas no experimento. Esta amostra foi composta por 3 sub-amostras de 30 ovos cada, para determinar a média de cada bandeja contendo 30 ovos. Desta média, foram então acrescidos $5 \%$ e subtraídos $5 \%$, determinando-se a faixa de peso dos ovos na qual foram selecionados para incubação de cada idade da matriz em separado, dentro de uma mesma máquina incubadora da marca CASP, modelo CM125. Após 19 dias de incubação os ovos foram transferidos para o nascedouro, também da marca CASP e modelo 23 I, respectivamente. Após o nascimento, os pintinhos, foram selecionados, conforme rotina do incubatório onde verificou-se cicatrização do umbigo, aparência geral e defeitos de conformação e sexagem. Somente então foram retirados 720 aves de cada idade de matriz avaliada, perfazendo um total de 3600 pintinhos utilizados no experimento, os quais foram transferidos do incubatório para o galpão experimental da Faculdade de Medicina Veterinária e Zootecnia, localizado em Botucatu, SP distante $90 \mathrm{~km}$ do incubatório.
O delineamento experimental adotado, foi o inteiramente casualizado em esquema fatorial $5 \times 2$, ou seja, 5 idades de matrizes (29, 41, 58, 68 e 98 semanas) e 2 sexos, com 4 repetições. Como o experimento previa o abate semanal de 5 aves/repetição, a partir da primeira semana foram alojados 90 pintinhos por boxe, num total de 40 parcelas; não houve reposição das aves mortas, sendo as mesmas utilizadas no final do experimento para cálculo da mortalidade.

As aves foram vacinadas no incubatório contra a doença de Marek e aos 10 dias de idade contra a doença de Newcastle, via água de bebida. A cama utilizada foi de maravalha e com uma espessura de aproximadamente $10 \mathrm{~cm}$.

As aves receberam ração (Tabela 1) e água à vontade durante todo o período de criação, que foi dividido em três fases: inicial de 1 a 21 dias, crescimento de 22 a 42 dias e final de 43 a 49 dias.

A análise estatística dos resultados foi realizada através do procedimento GLM (General Linear Models) do SAS [19].

TABELA 1. Composição calculada das rações utilizadas no experimento.

\begin{tabular}{lccc}
\hline \multicolumn{1}{c}{ Inicial } & Crescimento & Final \\
\hline Energia Metabolizável (kcal/kg) & 2980 & 3100 & 3200 \\
Proteína Bruta (\%) & 21,50 & 20,00 & 18,50 \\
Lisina (\%) & 1,25 & 1,10 & 1,00 \\
Metionina (\%) & 0,52 & 0,52 & 0,45 \\
Cálcio (\%) & 0,90 & 0,90 & 0,85 \\
Fósforo Disponível (\%) & 0,45 & 0,43 & 0,40 \\
\hline
\end{tabular}

\section{1 - Desenvolvimento do peito}

Para avaliação do desenvolvimento do peito foram abatidas cinco aves por tratamento semanalmente, a partir do primeiro dia do experimento (aves com um dia de vida) sendo que o peito com osso e carne foram utilizados para o cálculo da porcentagem de peito inteiro em relação ao peso da ave viva.

\section{2 - Rendimento de peito}

Essas determinações foram realizadas segundo metodologia descrita por MENDES [11]. Aos 21, 28, 35, 42 e 49 dias de idade foi retirada uma amostra de 5 aves por box, totalizando 25 aves por tratamento, para avaliação do rendimento de peito inteiro, carne de peito.

\section{3 - Características de qualidade da carne de pei- to e pernas}

Para a avaliação de peso, comprimento, largura, espessura, pH, perda de peso por cozimento e força de cizalhamento, foram amostradas 5 aves por box em cada idade de abate considerada. Essas determinações foram realizadas somente nas aves provenientes de matrizes com 29 e 68 semanas de idade. Esse procedimento foi adotado a fim de diminuir o número total de 
amostras a serem analisadas, e teve como objetivo principal verificar se existiam diferenças entre matrizes jovens (29 semanas) e velhas (68 semanas).

\section{4 - Peso, comprimento, largura e altura do peito}

Para as determinações do comprimento, largura e altura do peito, foi pesado o conjunto dos músculos peitorais, a fim de se avaliar o total e a percentagem de carne branca. A seguir, os músculos pectoralis major foram dissecados e pesados. O filé esquerdo foi medido quanto ao comprimento, largura e altura com o auxílio de um paquímetro, sendo que a altura foi medida na parte mais espessa do músculo.

\section{5 - pH}

A determinação do $\mathrm{pH}$ foi realizada através de eletrodo de penetração, diretamente no peito das aves, 24 horas post mortem. Essa medida foi feita em 5 aves de cada box, nas aves oriundas de matrizes com 29 e 68 semanas de idade.

\section{6 - Perda de peso por cozimento}

Para a determinação da perda de peso por cozimento e da força de cizalhamento, foi utilizado o músculo peitoral esquerdo da ave, o qual foi embalado em papel laminado e mantido numa chapa elétrica de modelo comercial, com aquecimento nas duas faces, por aproximadamente 8 minutos, a uma temperatura de $85^{\circ} \mathrm{C}$. Depois de uma hora, a amostra de peito foi pesada, obtendo-se assim, o peso uma hora após o cozimento. As amostras foram embaladas em papel absorvente e em sacos plásticos. Após 24 horas, as amostras foram desembaladas e novamente pesadas, obtendo-se o peso 24 horas após o cozimento. A diferença de peso entre o peso do peito in natura e o peso cozido com 1 e 24 horas após o cozimento correspondem à perda de peso por cozimento nos dois períodos [7].

\section{7 - Força de cizalhamento}

Para a determinação da força de cizalhamento (textura ou maciez) foram utilizadas as amostras usadas para a determinação da perda de peso por cozimento. Foram retiradas de 6 a 8 amostras na forma de paralelepípedos com $2 \times 2 \times 1,13 \mathrm{~cm}$, as quais foram colocadas com as fibras orientadas no sentido perpendicular às lâminas do aparelho Warner-Bratzler, conforme a técnica descrita por FRONING, BABJI \& MATHER [4].

\section{3 - RESULTADOS E DISCUSSÃO}

\section{1 - Desenvolvimento do peito de frangos de corte}

O desenvolvimento do peito de frangos de corte, em função da idade da matriz e do sexo, até os 49 dias de idade, é apresentado na Tabela 2.

O crescimento relativo do peito, em relação ao peso vivo das aves foi influenciado $(\mathrm{p}<0,05)$ pela idade da matriz somente aos 42 dias, onde as aves nascidas das matrizes com 41 semanas apresentaram crescimento de peito superior às aves nascidas das matrizes com 68 semanas, porém não diferiu $(\mathrm{p}>0,05)$ das demais aves. O sexo influenciou o crescimento do peito $(\mathrm{p}<0,05)$ aos 42 e 49 dias, sendo que os machos apresentaram maior crescimento aos 42 e menor aos 49 dias, com relação às fêmeas.

TABELA 2. Crescimento relativo do peito de frangos de corte nascidos de matrizes de diferentes idades (\%).

\begin{tabular}{|c|c|c|c|c|c|c|c|}
\hline \multirow{2}{*}{$\begin{array}{l}\text { Idade } \\
\text { (dias) }\end{array}$} & \multirow{2}{*}{ Sexo } & \multicolumn{5}{|c|}{ Idade da Matriz } & \multirow{2}{*}{ Médias } \\
\hline & & 29 & 41 & 58 & 68 & 98 & \\
\hline \multirow[t]{2}{*}{1} & Macho & 4.14 & 4.04 & 4.60 & 4.08 & 3.91 & 4.16 \\
\hline & Fêmea & 4.06 & 4.17 & 3.96 & 4.07 & 3.84 & 4.02 \\
\hline $13,90^{*}$ & Média & 4.10 & 4.10 & 4.28 & 4.07 & 3.88 & \\
\hline \multirow[t]{2}{*}{7} & Macho & 12.00 & 12.55 & 11.98 & 12.91 & 12.63 & 12.41 \\
\hline & Fêmea & 11.78 & 12.28 & 12.20 & 12.80 & 11.95 & 12.20 \\
\hline $5,12^{*}$ & Média & 11.88 & 12.41 & 12.09 & 12.85 & 12.28 & \\
\hline \multirow[t]{2}{*}{14} & Macho & 12.62 & 14.16 & 12.82 & 13.93 & 13.65 & 13.44 \\
\hline & Fêmea & 12.42 & 12.84 & 13.18 & 14.08 & 13.93 & 13.29 \\
\hline $8,87^{\star}$ & Média & 12.52 & 13.50 & 13.00 & 14.00 & 13.19 & \\
\hline \multirow[t]{2}{*}{21} & Macho & 16.20 & 16.23 & 15.71 & 16.00 & 15.61 & 15.95 \\
\hline & Fêmea & 15.80 & 15.74 & 15.06 & 16.03 & 16.16 & 15.75 \\
\hline $3,96^{*}$ & Média & 16.00 & 15.99 & 15.38 & 16.01 & 15.88 & \\
\hline \multirow[t]{2}{*}{28} & Macho & 17.46 & 17.51 & 17.33 & 17.15 & 16.87 & 17.26 \\
\hline & Fêmea & 16.89 & 17.16 & 17.23 & 17.42 & 16.99 & 17.14 \\
\hline $3,36^{*}$ & Média & 17.17 & 17.34 & 17.28 & 17.28 & 16.93 & \\
\hline \multirow[t]{2}{*}{35} & Macho & 17.67 & 18.31 & 17.20 & 17.24 & 16.83 & 17.45 \\
\hline & Fêmea & 17.49 & 17.12 & 17.05 & 17.38 & 17.53 & 17.31 \\
\hline $3,85^{\star}$ & Média & 17.58 & 17.72 & 17.13 & 17.31 & 17.18 & \\
\hline \multirow[t]{2}{*}{42} & Macho & 19.04 & 19.10 & 19.09 & 18.33 & 18.83 & $18.88^{A}$ \\
\hline & $\begin{array}{l}\text { Fêmea } \\
\text { Média }\end{array}$ & $\begin{array}{c}18.23 \\
18.64^{\mathrm{ab}}\end{array}$ & $\begin{array}{c}19.19 \\
19.14^{\mathrm{a}}\end{array}$ & $\begin{array}{c}18.91 \\
19.01^{\mathrm{ab}}\end{array}$ & $\begin{array}{c}17.93 \\
18.13^{b}\end{array}$ & $\begin{array}{c}18.11 \\
18.47^{a b}\end{array}$ & $18.47^{\mathrm{B}}$ \\
\hline \multirow[t]{2}{*}{49} & Macho & 19.16 & 18.65 & 18.49 & 18.46 & 18.66 & $18.68^{B}$ \\
\hline & Fêmea & 18.84 & 19.23 & 18.84 & 18.93 & 19.06 & $18.98^{A}$ \\
\hline $2,28^{*}$ & Média & 19.00 & 18.94 & 18.67 & 18.70 & 18.86 & \\
\hline
\end{tabular}

Médias seguidas de letras diferentes, minúsculas nas linhas e maiúsculas nas coluMédias seguidas de letras diferentes, minúsculas
nas, diferem entre si pelo teste Tukey $(\mathrm{p}<0.05)$.
* Coeficiente de variação $(\%)$.

As curvas de crescimento do peito de machos e fêmeas em função da idade podem ser vistas nas Figuras $1 e 2$.

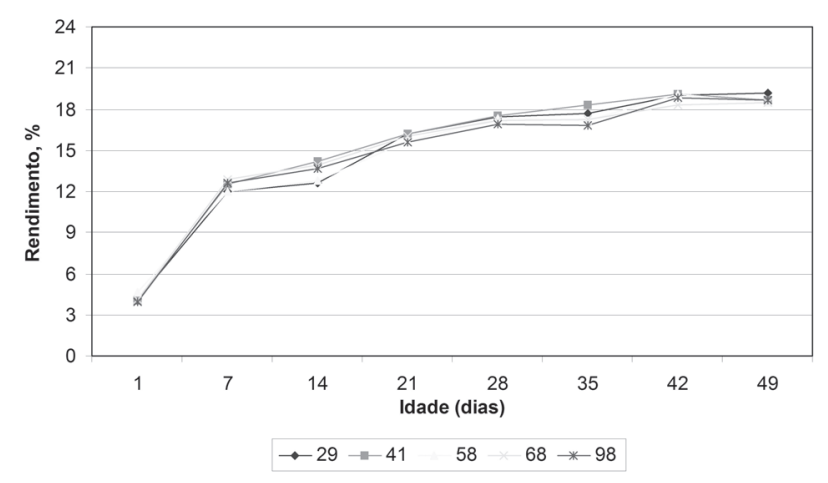

FIGURA 1. Curva de crescimento relativo do peito de frangos de corte, machos nascidos de matrizes com diferentes idades. 


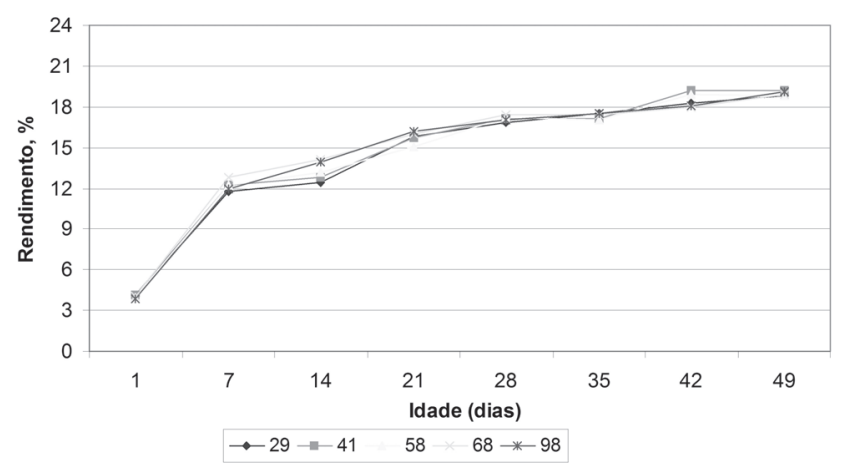

FIGURA 2. Curva de crescimento relativo do peito de frangos de corte, fêmeas nascidas de matrizes com diferentes idades.

\section{2 - Rendimento de carne de peito}

Na Tabela 3, verifica-se que de forma semelhante ao rendimento do peito, a idade da matriz influenciou $(\mathrm{p}<0,05)$ o rendimento da carne do peito somente quando as aves foram abatidas com 49 dias $(p<0,05)$, sendo que as aves nascidas das matrizes com 29 semanas apresentaram rendimento superior às aves nascidas de matrizes com 58 e 68 semanas.

TABELA 3. Rendimento de carne de peito (\%) de frangos de corte oriundos de matrizes de diferentes idades.

\begin{tabular}{|c|c|c|c|c|c|c|c|c|}
\hline \multirow{2}{*}{$\begin{array}{c}\text { Idade de } \\
\text { Abate (dias) }\end{array}$} & \multirow[t]{2}{*}{ Sexo } & \multicolumn{5}{|c|}{ Idade da Matriz (semanas) } & \multirow[t]{2}{*}{ Médias } & \multirow{2}{*}{$\begin{array}{l}\text { C.V. } \\
(\%)\end{array}$} \\
\hline & & 29 & 41 & 58 & 68 & 98 & & \\
\hline \multirow{3}{*}{21} & Macho & 23,17 & 23,10 & 22,68 & २2,94 & 22,60 & 22,90 & \\
\hline & Fêmea & २3,२2 & 22,73 & 22,52 & 23,43 & 23,45 & 23,07 & 2,90 \\
\hline & Média & 23,20 & 22,92 & 22,60 & 23,18 & 23,02 & & \\
\hline \multirow{3}{*}{28} & Macho & 24,27 & 24,07 & 25,06 & 23,68 & 24,03 & 24,22 & \\
\hline & Fêmea & 23,79 & 24,51 & 24,12 & 24,37 & 24,04 & 24,17 & 4,34 \\
\hline & Média & 24,03 & 24,29 & 24,59 & 24,03 & 24,03 & & \\
\hline \multirow{3}{*}{35} & Macho & 24,07 & 25,14 & 24,14 & 24,10 & 23,55 & 24,20 & \\
\hline & Fêmea & 24,33 & 24,48 & 24,98 & 24,56 & 24,71 & 24,61 & 3,13 \\
\hline & Média & 24,20 & 24,81 & 24,56 & 24,33 & 24,13 & & \\
\hline \multirow{3}{*}{42} & Macho & 25,46 & 25,66 & 25,80 & 25,03 & 25,57 & $25,50^{B}$ & \\
\hline & Fêmea & 26,27 & 26,27 & 26,75 & 25,78 & 25,98 & $26,21^{A}$ & 2,49 \\
\hline & Média & 25,86 & 25,96 & 26,28 & 25,40 & 25,78 & & \\
\hline \multirow{3}{*}{49} & Macho & 26,07 & 24,79 & 25,26 & 24,14 & 24,84 & $25,02^{B}$ & \\
\hline & Fêmea & 27,46 & 27,00 & 25,70 & 25,97 & 26,34 & $26,49^{A}$ & 3,31 \\
\hline & Média & $26,76^{a}$ & $25,90^{\mathrm{ab}}$ & $25,48^{b}$ & $25,05^{b}$ & $25,59^{a b}$ & & \\
\hline
\end{tabular}

Médias seguidas de diferentes letras minúsculas nas linhas e maiúsculas nas colunas diferem entre si pelo teste Tukey $(\mathrm{p}<0,05)$.

Os melhores resultados para carne de peito ocorreram principalmente nas fêmeas nascidas de matrizes com 29 e 41 semanas. Provavelmente, tais resultados ocorrem em função do maior rendimento para peito inteiro, que após a retirada da pele e dos ossos, originou a carne de peito. O sexo teve influência $(\mathrm{p}<0,05)$ sobre o rendimento da carne do peito, tanto aos 42 como aos 49 dias, sendo que as fêmeas apresentaram rendimentos superiores aos dos machos. Estes dados estão de acordo com os encontrados por GARCIA et al. [5], MENDES et al. [12] e MOREIRA et al. [14].

\section{3 - Medidas físicas do peito}

Na Tabela 4, encontram-se as determinações físicas dos filés de peito das aves abatidas dos 21 aos 49 dias de idade, sendo que aos 21 dias observam-se um efeito significativo $(\mathrm{p}<0,05)$ da idade da matriz, sendo que o comprimento do filé das aves nascidas de matrizes com 68 semanas foi maior que os filés das aves nascidas de matrizes com 29 semanas. Já aos 42 dias de idade, houve interação significativa $(p<0,05)$ entre idade da matriz e sexo para o comprimento do filé, onde os machos foram superiores às fêmeas e as aves nascidas de matrizes com 29 semanas foram superiores às aves nascidas de matrizes com 68 semanas. O sexo afetou $(\mathrm{p}<0,05)$ a largura do filé, que foi maior para os machos que para as fêmeas, aos 49 dias de idade, onde houve interação significativa $(\mathrm{p}<0,05)$, entre a idade da matriz e o sexo para a largura do peito, sendo que as aves oriundas de matrizes com 29 semanas foram superiores as aves nascidas de matrizes com 68 semanas.

TABELA 4. Determinações físicas $(\mathrm{cm})$ de filés de peito de frangos de corte nascidos de matrizes com diferentes idades, abatidas aos $21,28,35,42,49$ dias de idade.

\begin{tabular}{|c|c|c|c|c|c|c|c|}
\hline \multirow{2}{*}{ Parâmetro } & \multirow{2}{*}{ Sexo } & \multirow{2}{*}{$\begin{array}{c}\text { Idade da } \\
\text { Matriz(sem) }\end{array}$} & \multicolumn{5}{|c|}{ Idade dos frangos (dias) } \\
\hline & & & 21 & 28 & 35 & 42 & 49 \\
\hline \multirow{6}{*}{ Espessura } & Macho & 29 & 0,98 & 1,18 & 1,41 & 1,80 & 1,95 \\
\hline & Fêmea & 29 & 0,89 & 1,02 & 1,34 & 1,66 & 1,76 \\
\hline & Média & & 0,94 & 1,10 & 1,38 & 1,73 & 1,85 \\
\hline & Macho & 68 & 0,98 & 1,16 & 1,46 & 1,83 & 2,02 \\
\hline & Fêmea & 68 & 0,94 & 1,12 & 1,37 & 1,60 & 1,84 \\
\hline & Média & & 0,96 & 1,14 & 1,41 & 1,72 & 1,93 \\
\hline \multirow{6}{*}{ Largura } & Macho & 29 & 5,26 & 6,25 & 6,90 & 7,50 & $8,98^{A}$ \\
\hline & Fêmea & 29 & 5,11 & 5,98 & 6,55 & 6,98 & $8,26^{\mathrm{B}}$ \\
\hline & Média & & 5,19 & 6,11 & 6,72 & 7,24 & 8,62 \\
\hline & Macho & 68 & 5,39 & 6,47 & 6,95 & 7,55 & 8,61 \\
\hline & Fêmea & 68 & 5,19 & 6,06 & 6,85 & 7,20 & 8,47 \\
\hline & Média & & 5,25 & 6,27 & 6,90 & 7,35 & 8,54 \\
\hline \multirow{6}{*}{ Comprimento } & Macho & 29 & 10,41 & 12,75 & 15,04 & $16,76^{A}$ & 18,15 \\
\hline & Fêmea & 29 & 9,92 & 11,76 & 14,29 & $15,25^{B}$ & 16,63 \\
\hline & Média & & $10,17^{\mathrm{b}}$ & 12,26 & 14,67 & 16,01 & 17,39 \\
\hline & Macho & 68 & 10,66 & 13,23 & 15,20 & 16,47 & 18,36 \\
\hline & Fêmea & 68 & 10,50 & 11,94 & 14,48 & 15,85 & 17,03 \\
\hline & Média & & $10,58^{\mathrm{a}}$ & 12,59 & 14,84 & 16,16 & 17,69 \\
\hline
\end{tabular}
Médias seguidas de letras diferentes minús
diferem entre si pelo teste Tukey $(\mathrm{p}<0,05)$

Conforme demonstrado na literatura, o comprimento, espessura e peso do filé de peito de frangos de corte são afetados pela linhagem, sexo e idade das aves, sendo que esses resultados são semelhantes aos encontrados neste trabalho onde as aves nascidas de matrizes com 68 semanas apresentaram filés maiores que as aves nascidas de matrizes com 29 semanas. O sexo também afetou a espessura e o comprimento dos filés, resultados estes próximos aos encontrados por LUBRITZ [10].

\section{4 - Perda de peso por cozimento, força de cisa- lhamento e pH da carne}

Na Tabela 5, são apresentadas as determinações relacionadas com a qualidade da carne dos 21 aos 49 dias de idade, onde aos 21 dias somente o sexo afetou $(\mathrm{p}<0,05)$ o $\mathrm{pH}$ do peito e da perna, que foram superiores 
para os machos quando comparados com as fêmeas. Resultados semelhantes foram encontrados por MENDES et al. [13] onde os machos apresentaram maiores valores de $\mathrm{pH}$ que as fêmeas.

TABELA 5. Qualidade da carne de peito e pernas de frangos de corte nascidos de matrizes de diferentes idades e abatidas aos $21,28,35,42$ e 49 dias.

\begin{tabular}{|c|c|c|c|c|c|c|c|}
\hline \multirow{2}{*}{ Parâmetro } & \multirow[b]{2}{*}{ Sexo } & \multirow{2}{*}{$\begin{array}{l}\text { Idade da } \\
\text { Matriz }\end{array}$} & \multicolumn{5}{|c|}{ Idade do Abate (dias) } \\
\hline & & & 21 & 28 & 35 & 42 & 49 \\
\hline \multirow{6}{*}{$\begin{array}{l}\text { Perda de peso } \\
\text { Por cozimento (\%) }\end{array}$} & Macho & 29 & 22,59 & 22,35 & 21,37 & 17,97 & 17,35 \\
\hline & Fêmea & 29 & 20,24 & 22,60 & 20,85 & 17,97 & 16,56 \\
\hline & Média & & 21,41 & 22,48 & 21,11 & 17,97 & 16,96 \\
\hline & Macho & 68 & 22,43 & 22,95 & 21,46 & 18,76 & 16,97 \\
\hline & Fêmea & 68 & 21,47 & 24,00 & 21,20 & 19,19 & 16,80 \\
\hline & Média & & 21,95 & 23,47 & 21,33 & 18,98 & 16,89 \\
\hline \multirow{6}{*}{$\begin{array}{l}\text { Força de } \\
\text { Cizalhamento } \\
\left(\mathrm{kf} / \mathrm{cm}^{2}\right)\end{array}$} & Macho & 29 & 1,24 & 1,69 & 2,10 & 2,17 & 2,67 \\
\hline & Fêmea & 29 & 1,22 & 1,51 & 1,85 & 2,20 & 2,61 \\
\hline & Média & & 1,23 & 1,60 & 1,98 & 2,18 & 2,64 \\
\hline & Macho & 68 & 1,34 & 1,70 & 2,09 & 2,11 & 2,76 \\
\hline & Fêmea & 68 & 1,23 & 1,53 & 1,97 & 2,13 & 2,80 \\
\hline & Média & & 1,29 & 1,61 & 2,03 & 2,12 & 2,78 \\
\hline \multirow{6}{*}{$\mathrm{pH}$ do peito } & Macho & 29 & 5,98 & 6,03 & 6,07 & 6,08 & 5,94 \\
\hline & Fêmea & 29 & 5,85 & 5399 & 6,04 & 5,98 & 5,86 \\
\hline & Média & & 5,91 & 6,01 & 6,05 & $6,02^{\mathrm{A}}$ & 5,90 \\
\hline & Macho & 68 & 5,99 & 6,02 & 6,11 & 6,01 & 5,91 \\
\hline & Fêmea & 68 & 5,86 & 5,98 & 6,04 & 5,96 & 5,86 \\
\hline & Média & & 5,92 & 6,00 & 6,08 & $5,98^{\mathrm{B}}$ & 5,88 \\
\hline \multirow{6}{*}{$\mathrm{pH}$ da perna } & Macho & 29 & 6,07 & 6,12 & 6,09 & 6,19 & 6,05 \\
\hline & Fêmea & 29 & 5,89 & 6,08 & 6,09 & 6,07 & 6,03 \\
\hline & Média & & 5,98 & 6,10 & 6,09 & 6,13 & 6,04 \\
\hline & Macho & 68 & 6,08 & 6,10 & 6,15 & 6,16 & 5,99 \\
\hline & Fêmea & 68 & 5,91 & 6,06 & 6,07 & 6,02 & 5,91 \\
\hline & Média & & 5,99 & 6,08 & 6,11 & 6,09 & 5,95 \\
\hline
\end{tabular}

Aos 28 dias de idade, o sexo afetou $(\mathrm{p}<0,05)$ a força de cizalhamento que foi maior para os machos que para as fêmeas. Já aos 35 dias de idade, o sexo influenciou $(\mathrm{p}<0,05)$ a força de cizalhamento e o pH do peito, quando as duas medidas avaliadas foram maiores para os machos que para as fêmeas. Aos 42 dias a idade da matriz afetou $(\mathrm{p}<0,05)$ o $\mathrm{pH}$ do peito, que foi maior nas aves oriundas de matrizes com 29 semanas que nas aves oriundas de matrizes com 68 semanas. Já o sexo, afetou $(\mathrm{p}<0,05)$ o $\mathrm{pH}$ do peito e o $\mathrm{pH}$ da perna que foram maiores para os machos que para as fêmeas.

Os resultados encontrados são contrários aos observados por MOREIRA et al. [15] e MENDES et al. [13] onde o sexo não afetou os valores de $\mathrm{pH}$. Com relação à idade da matriz, esta afetou o $\mathrm{pH}$ da carne de peito, mas nenhum dado semelhante foi encontrado na literatura.

Nas medidas da qualidade da carne de frangos abatidos aos 49 dias, a idade da matriz afetou $(\mathrm{p}<0,05)$ o $\mathrm{pH}$ da perna, que foi maior nas aves nascidas de matrizes com 29 semanas, que nas aves nascidas de matrizes com 68 semanas. Porém, o sexo afetou $(\mathrm{p}<0,05)$ o $\mathrm{pH}$ do peito e da perna, que foram superiores para os machos quando comparados com as fêmeas.

Resultados opostos foram encontrados por GARCIA [6], onde o $\mathrm{pH}$ da carne de peito e perna das fêmeas foram maiores que nos machos; no presente trabalho, o pH das fêmeas foi menor tanto para carne de peito como para pernas.
A perda de peso por cozimento nos músculos do peito de frangos de corte é uma característica que, de acordo com alguns autores, pode ser significativamente influenciada pelas temperaturas elevadas durante o período de criação e no período pré-abate.

Após o abate do animal e em condições normais, o sistema tampão bicarbonato perde sua eficiência, uma vez que é baseado em troca do meio sangüíneo; entretanto, o sistema tampão fosfato tende a resistir às alterações de $\mathrm{pH}$ entre 6,1 e 7,4. A importância para o organismo em manter o relativo equilíbrio ácido básico significa manter os complexos enzimáticos atuantes por um maior período de tempo [8]. O problema mais comumente encontrado na carne de peito de frangos de corte atualmente é a maciez. Isto geralmente é decorrente de alterações na estrutura miofibrilar, determinadas pelo aparecimento rápido do rigor mortis em função do estresse pré-abate. Neste trabalho, a força de cizalhamento foi afetada somente pelo sexo, onde os machos foram superiores, mostrando uma menor maciez em relação às fêmeas e somente em duas idades de abate, com 28 e 35 dias de idade.

\section{4 - CONCLUSÕES}

A idade da matriz influenciou o crescimento, o rendimento, a espessura, o comprimento e o $\mathrm{pH}$ do peito, assim como o $\mathrm{pH}$ das pernas também foi afetado pela idade da matriz nas diferentes idades de abates avaliadas.

\section{5 - REFERÊNCIAS BIBLIOGRÁFICAS}

[[1] BARRETO, S. L. T. Níveis de proteina e vitamina $\mathbf{E}$ para matrizes de frango de corte na fase de produção. 1998. 173. Tese (Doutorado) - Escola de Veterinária, Universidade Federal de Minas Gerais

[2] CANÇADO, S. V.; BAIÃO, N. C.; JUNIOR, J. G. F.; ZUIN, A. H. L.; MARTINS, C. A.; NETO, M. H. Ácido linoleico na alimentação de matriz pesada. Efeitos sobre: peso do ovo, incubação, relação peso da gema/peso do ovo e qualidade dos pintos.In: CONFERÊNCIA APINCO DE CIÊNCIA TECNOLOGIA AVÍCOLA, 1995, Campinas.Trabalhos de Pesquisa.Campinas: Fundação APINCO de Ciência e Tecnologia Avícolas, 1995. p127-128.

[3] Froning, G.; W., BABJi, A. S.; MATHER, F.B. The effect of preslaughter temperatures, stress, struggle and anesthetization on color and textural characteristics of turkey muscle. Poultry Science, Champaign, 1978. v.57, n.3, p.630-633.

[4] Garcia, E. A.; Mendes, A. A.; SIlva, A. B. P.; GONZALES, E. Efeito do nível de energia da dieta e do sexo sobre o rendimento de carcaça de frangos de corte. Veterinária e Zootecnia, São Paulo, 1993. v.5, p.2937.

[5] GARCIA, R. G. Avaliação do desempenho, características de carcaça e análise econômica da criação de frangos de corte em diferentes densidades. 2002. 97. Tese (Mestrado) - Faculdade de Medicina Veterinária e Zootecnia, Universidade Estadual Paulista.

[6] HONIKEL, K.O. The water binding of meat. Fleischwirttsch, Frankfurt, 1987. v.67, p.1098-1102. 
[7] LEHNINGER, A. L.; NELSON, D.L.; COX, M. M. Princípios de Bioquimica (ed). Savier. Traduzido por W. R. Lodie, A. A. Simões. São Paulo. Brasil. Tradução de Principles of Biochemistry, 839p, 1995.

[8] LE BIHAN-DUVAL E, MILLET N, Remignon H. Broiler meat quality: Effect of selection for increased carcass quality and estimates of genetic parameters. Poultry Science, 1999; v.78, p.822-826.

[9] LUBRITZ, S. L. A statistical model for white meat yield in broiler. Journal Applied Poultry Research., 1997. v.6,p. 253-59.

[10] MENDES, A. A. Efeito de fatores genéticos, nutricionais e de ambiente sobre o rendimento de_carcaça de frangos de corte. 1990. 103. Tese (Livre Docência)Faculdade de Medicina Veterinária e Zootecnia, Universidade Estadual Paulista.

[11] MENDES, A. A.; GARCIA, E. A.; GONZALES, E.; SILVA, A. B. P. Efeito do peso de abate sobre o rendimento de carcaça de frangos de corte. Veterinária e Zootecnia, São Paulo, 1993. v. 5, p. 77-82.

[12] MENDES, A. A.; MOREIRA, J.; ROÇA, R. O.; GARCIA, E. A.; NAAS, I. A.; ALMEIDA, I. C. L.; GARCIA, R. G. Efeito da taxa de lotação e nível de energia da dieta sobre o desempenho, rendimento de carcaça e análise econômica em frangos de corte. Revista Brasileira de Ciência Avícola, Campinas, 2002. suplemento 4, p.4.

[13] MOREIRA, J.; MENDES, A. A; GARCIA, R. G.; NAAS, I. A.; MIWA, I.; GARCIA, E. A.; TAKITA, T. S.; ALMEIDA, I. C. L Efeito da densidade de criação e do nível de energia da dieta sobre o desempenho e rendimento de carcaça em frangos de corte. Revista Brasileira de Ciência Avícola, Campinas, 2001. suplemento 3, p.39.

[14] MOREIRA, J.; MENDES, A. A; ROÇA, R. O.; NAAS, I. A.; PELICIA, K.; GARCIA, R. G.; ALMEIDA, I. C. L.
Efeito da densidade, linhagem, sexo e nível de energia da dieta sobre o rendimento e qualidade da carne de peito em frangos de corte. Revista Brasileira de Ciência Avícola, Campinas, 2002. suplemento 4, p.3.

[15] PEEBlES, E. D.; DOYLE, S. M.; PANSKY, T,; GERARD, P. D.; LATOUR, M. A.; BOYLE, C. R.; SMITH, T. W. Effects of breeder age and dietary fat on subsequent broiler performance. 2. Slaughter Yield. Poultry Science, Champaign, 1999. v.78, n.4, p 512-515.

[16] POOLE, G. H. Evaluation of age, gender, strain, and diet on the cooked yield and shear values of broiler breast fillets. Journal Applied Poultry Research, 1999; v. 8, p.170-176.

[17] ROQUE, L.; SOARES, M. C. Effects of eggshell quality and broiler breeder age on hatchability. Poultry Science, Champaign, 1994. v.73, n.12, p.1838-1845.

[18] SAS Institute, SAS user's Guide. Cary, NC, 1991.

[19] SINCLAIR, R. W.; ROBINSON F. E.; HARDIN, R. T. The effects of parentage post hatch treatment on broiler performance. Poultry Science, Champaign, 1989. v.69, n.4,p.526-534.

[20] VIEIRA, S. L. Idade da matriz, tamanho do ovo e desempenho do pintinho. In: CONFERENCIA APINCO DE CIÊNCIA E TECNOLOGIA AVÍCOLAS, 2001, Campinas. Anais. Campinas: Fundação APINCO de Ciência e Tecnologia Avícolas, 2001.v.2, p.117-123.

[21] VIEIRA, S. L.; MORAN Junior; E. T. Broiler yields using chicks hatched from egg weight extremes and diverse strains. Journal of Applied Poultry Research, Athens, 1998. v.7, n.4, p.339-346.

[22] WILSON, H. R. Interrelationships of egg size, chick size, post hatching growth and hatchability. World's Poultry Science Journal, London, 1991. v.47, n.1, p.5-20. 